\title{
Decompressive Craniectomy in Herpes Simplex Encephalitis: A Case Report and Review of Literature
}

Pasupula Venkataswamy ${ }^{*}$, Sachin Sureshbabu, Venkata Subbaiah Chaudhary, Sai Sudarshan, Rabindranath Tagore, Sukumara Sura, and Bala Rajashekhar STAR Hospitals, Banjara Hills, Hyderabad, India

*Corresponding author: Pasupula Venkataswamy, Senior Consultant-Neurologist, STAR Hospitals, Banjara Hills, Hyderabad, India, Tel: 7838785242; E-mail: consecrated77@yahoo.com

Rec date: Oct 10, 2016; Acc date: Oct 20, 2016; Pub date: Oct 23, 2016

Copyright: @ 2016 Venkataswamy P. This is an open-access article distributed under the terms of the Creative Commons Attribution License, which permits unrestricted use, distribution, and reproduction in any medium, provided the original author and source are credited.

\begin{abstract}
Herpes Simplex encephalitis is eminently treatable viral encephalitis which can rarely be complicated by a tumefactive inflammatory focus. The treatment strategy in this event should be aggressive to prevent immediate fatality as well as long term sequele. A 43-year-old woman with HSE developed new onset focal deficit with altered sensorium on the fourth day of illness despite early initiation of antiviral treatment. Imaging revealed right temporal and insular involvement with mass effect and midline shift. Decompressive craniectomy and temporal lobe biopsy was performed on emergent basis. The patient made remarkable clinical recovery subsequently. The report is presented for highlighting this rare complication as well as to reinstate the belief in surgical decompression as the preferred choice of treatment.
\end{abstract}

Keywords: Craniectomy; Simplex encephalitis; Surgical decompression

\section{Introduction}

Herpes simplex encephalitis is the one of the most common form of viral encephalitis across all races and age groups. The morbidity and mortality of this disorder has been significantly brought down with the advent of the highly effective anti-viral agent Acyclovir. However, complications like non-convulsive status epilepticus and raised intracranial pressure can claim lives in a proportion of cases especially in a setting where scrupulous monitoring of patients are not performed. We report an illustrative case where timely surgical intervention was associated with excellent clinical outcome.

\section{Case Report}

A 43-year-old housewife hailing from a rural district in Southern India was apparently well four days back when she developed high grade fever accompanied by altered sensorium 12-14 hours into the illness. Initial evaluation at a local center revealed no objective neurological deficits and a normal contrast enhanced CT of the brain. After a day of conservative management, MR imaging was conducted which revealed right temporal and insular hyper-intensities consistent with herpes simplex encephalitis (Figure 1). This prompted the initiation of $30 \mathrm{mg} / \mathrm{kg} / \mathrm{d}$ of Acyclovir. On day 2, she had a seizure in the form of vacant stare associated with tonic-clonic movements of left upper limb before generalization. Post ictal left hemiplegia and confusion lasted for an hour. The clinical course deteriorated further on day 4 with new onset left hemiplegia and a steady worsening of sensorium. At this point, the patient was shifted to our facility. On arrival, she was hemodynamically stable; systemic examination was unremarkable except for poor respiratory effort; Neurological examination revealed Glasgow coma scale (GCS) of 4(E1M2V1); Right pupil was dilated and unreacting; right plantar was extensor and left mute. An MRI of brain was immediately performed after intubation which showed right temporal edema compressing the brainstem.
Decompressive craniectomy was undertaken urgently along with temporal lobe biopsy. Postoperatively, patient was continued on antiviral (Acyclovir) $30 \mathrm{mg} / \mathrm{kg}$ along with intravenous antibiotics, antiepileptics and cerebral decongestants. Cerebrospinal fluid (CSF) examination revealed lymphocytic pleocytois (12 cells; $100 \%$ lymphocytes) with increased protein $(98 \mathrm{mg} / \mathrm{dl})$ and mildly reduced sugar $(40 \mathrm{mg} / \mathrm{dL})$ along with HSV PCR positivity.

After 2 weeks of treatment patient became conscious, coherent; able to walk without support and started accepting oral feeds. Histopathological examination of the temporal lobe specimen confirmed the diagnosis of HSE (Figure 2). Immunohistochemistry showed strongly positive HSV antigen in several neurons and oligodendroglial cells.

\section{Discussion}

Herpes simplex virus is a neurotropic DNA virus responsible for about $10 \%$ to $20 \%$ cases of viral encephalitis worldwide. Neurological manifestations occur after a viral prodrome in the form of altered sensorium, headache, seizures and or focal neurological deficits. MRI is the imaging modality of choice and characteristically shows T2/Flair hyperintense lesion in either or both temporal lobes, insula and frontal regions which may be accompanied by surrounding oedema and hemorrhage [1-4]. The EEG findings usually parallel the imaging abnormalities with focal slowing, periodic lateralized discharges (PLEDS), bilateral independent PLEDS (BiPLEDS) and occasionally NCSE [5]. CSF examination may reveal RBCs in addition to lymphocytic pleocytosis, mild to moderately elevated protein and normal glucose (can be low in a small proportion). Demonstration of viral DNA in CSF by polymerase chain reaction is the gold standard for diagnosis. Biopsy although not required for diagnosis is confirmatory especially when coupled with immune-histochemical stains for identification of viral inclusions. Despite the encouraging benefit of acyclovir, a significant number of patients suffer from long term cognitive and behavioural deficits and seizures (30-40\%) while $10 \%$ to $20 \%$ succumb to the illness $[3,4,6]$. 
Citation: Venkataswamy P, Sureshbabu S, Chaudhary VS, Sudarshan S, Tagore R, et al. (2016) Decompressive Craniectomy in Herpes Simplex Encephalitis: A Case Report and Review of Literature. J Neurol Disord 4: 310. doi:10.4172/2329-6895.1000310

Page 2 of 2

There are two clinical situations in which surgical decompression is useful in HSE: 1) Raised intracranial tension intractable to medical management 2) A tumefactive lesion causing significant oedema, mass effect and midline shift. The latter, as observed in our patient, is usually the result of hemorrhagic necrosis in the affected brain tissue. However, these scenarios are an uncommon occurrence in HSE. Nevertheless, early detection is key to a successful outcome in these potentially life-threatening complications. Two mechanisms justify this form of treatment-firstly, it prevents impingement of the brain against dural or bony structures and secondly it improves cerebral perfusion thus preventing superadded ischemic injury $[7,8]$. Yan reported two cases where surgical decompression was performed late in the course of illness, in the event of impending uncal herniation, both of which was associated with a good long term outcome. 8 Rabelino et al. described two similar situations in young patients with a late increase in ICP, but they observed a delayed cognitive recovery [9]. Other authors have reported hemicraniectomy performed in the first week after the patients developed hemiparesis, worsening sensorium, loss of corneal reflex and papillary abnormalities which was associated with good neurological recovery thus reinforcing the role of this treatment modality [10]. Anterior temporal lobectomy is another surgical option in fulminant cases with significant mass effect and midline shift [11]. The overall outcomes achieved are far better than that observed with even the most aggressive medical strategies to lower ICT in previous reports [7-13]. A summary of the published literature on surgical outcome of decompressive craniectomy is presented in table 1. However early detection of raised intracranial pressure would allow prophylactic decompression before clinical worsening which would be the ideal approach. For this purpose, the role of invasive methods like ICP monitoring as well as non-invasive tools like CT perfusion and transcranial Doppler need to be explored.

\section{Conclusion}

Early and aggressive surgical management of raised intracranial pressure and mass effect is associated with good and meaningful outcomes in patients with HSE.

\section{References}

1. Satish Chandra P, Ravi V, Shankar SK (1996) Herpes simplex encephalitis: Clinico-pathological and virological appraisal. Progress in Clinical Neuro Sciences 11: 167-186.

2. Panagariya A, Jain RS, Gupta S, Garg A, Sureka RK, et al. (2001) Herpes simplex encephalitis in North West India. Neurol India 49: 360-365.

3. Raschilas F, Wolff M, Delatour F, Chaffaut C, De Broucker T, et al. (2002) Outcome of and prognostic factors for herpes simplex encephalitis in adult patients: results of a multicenter study. Clin Infect Dis 35: 254-260.

4. Riera-Mestre A, Gubieras L, Martínez-Yelamos S, Cabellos C, FernándezViladrich P (2009) Adult herpes simplex encephalitis: fifteen years' experience. Enferm Infecc Microbiol Clin 27: 143-147.

5. Lai CW, Gragasin ME (1988) Electroencephalography in herpes simplex encephalitis. J Clin Neurophysiol 5: 87-103.

6. Mc Grath N, Anderson NE, Croxson ML (1997) Herpes simplex encephalitis treated with acyclovir: diagnosis and long term outcome. J Neurol Neurosurg Psychiatry 63: 321-326.

7. Schwab S, Jünger E, Spranger M (1997) Craniectomy: An aggressive treatment approach in severe encephalitis. Neurology 48: 412-417.

8. Yan HJ (2002) Herpes simplex encephalitis: The role of surgical decompression. Surg Neurol 57: 20-24.

9. González Rabelino GA, Fons C, Rey A, Roussos I, Campistol J (2008) Craniectomy in herpetic encephalitis. Pediatr Neurol 39: 201-203.

10. Taferner E, Pfausler B, Kofler A (2001) Craniectomy in severe, lifethreatening encephalitis: A report on outcome and long term prognosis of four cases. Intensive Care Med 27: 1426-1428.

11. Adamo M, Deshaies E (2008) Emergency decompressive craniectomy for fulminating infectious encephalitis. Report of two cases. J Neurosurg 108: 174-176.

12. Midi I, Tuncer N, Midi A, Mollahasanoglu A, Konya D, et al. (2007) Effects of decompressive surgery on prognosis and cognitive deficits in herpes simplex encephalitis. Behav Neurol 18: 245-249.

13. Barnett GH, Ropper AH, Romeo J (1998) Intracranial pressure and outcome in adult encephalitis. J Neurosurg 68: 585-588. 